\title{
Excavation support - geotechnical failures in the context of design and execution errors as well as formal and economic conditions
}

\author{
Natalia Maca $^{1, *}$ and Jakub Sierant ${ }^{1}$ \\ ${ }^{1}$ TITAN POLSKA Sp. z o.o., Miłkowskiego 3/801, 30-349 Kraków, Poland
}

\begin{abstract}
Deep excavations carried out in the difficult ground conditions, demand particular care both in a design and execution phase, as well as reliably conducted supervision by personnel having the appropriate skill and experience, but also well-defined responsibility map. In the paper the consequences in omissions in some of these aspects are presented. Description of several deep excavation projects implemented with different techniques and in various ground conditions, in which failure or pre-failure state occurred are introduced. The results of the analysis failure causes analysis are characterized. On that basis, the tendencies in the scope of the most frequently occurring causes of failures in geotechnical project carried out in Poland are defined. Finally, an attempt is made to indicate the direction of changes needed in order to improve the situation - to reduce the number of construction failures in geotechnical projects. The paper contains also observations about uniqueness of the geotechnical structures comparing to other branches of civil engineering works and highlights risks and sources of problems in deep excavation projects. The discussion about vulnerability and high percentage of failure in that kind of projects in context of formal end economical conditions of public tender procedures is presented.
\end{abstract}

\section{Preface}

Recently, in geotechnical projects carried out in Poland an alarming trend of the increase in the number of failures and broadly understood pre-failure states (exceeding limits of displacement, excessive deformations, damage to adjacent structures) is observed. On the one hand, this is understandable, as in general it is now being built in increasingly difficult geotechnical conditions, more and more quickly, and at the same time structures are becoming more and more demanding, so securing excavations is an increasing design and execution challenge. On the other hand, the quality of ground investigation, computational techniques and support of standards are becoming more and more advanced and accurate, reflecting the work of these structures more reliably. At the same time, it seems that the percentage of failures in geotechnics is much higher than in other areas of construction and occur predominantly in public projects. Therefore, a very justified question arises about the reasons for this state of affairs.

It should be noted, that excavation support structures, like all geotechnical structures, are burdened with a significant risk resulting from the nature of the soil as a construction material

\footnotetext{
* Corresponding author: natalia.maca@,titan.com.pl
} 
and generally the lack of access to the structure after its construction. Therefore, not only geotechnical standards obligate the designers to use relatively higher values of partial factors and detailed technique and material specification, but also emphasize the meaning of supervision, quality control and monitoring on site as particularly important. This on-site actions with decision-making scheme are crucial, as are the only way to identify unfavourable phenomena at an early stage and to intervene to eliminate potential threats before mass movements are activated. However it seems, that actually the level of accuracy and precaution in the majority od projects decreases with the advancement of the project life cycle - being the highest at the design stage, decreasing during construction and minimizing at the operation of the facility. This situation is in clear contradiction with normative regulations, according to which the geotechnical structures, such as excavation support, demand particular care, beginning from a phase of ground investigations, through a design and execution phase, as well as cooperation between designers, geotechnical engineers and contractor, what ultimately contributes to increasing the risk.

The paper describes selected examples of emergency conditions of excavation protection structures, carried out using various techniques, which reflect the observed - in authors' practice - tendencies in the scope of the most frequently occurring causes of failures. All examples are characterized in terms of object characteristics and ground conditions, the description of the emergency situation is presented, as well as conclusions from the analysis of the causes of the failures.

\section{Failure of shoring of deep excavation for an office building}

\subsection{Design solution and geotechnical conditions}

The building office with two storey underground had to be constructed in the open-pit trench of $8000 \mathrm{~m}^{2}$. The excavation depth, as the terrain is decreasing was variable between $8 \mathrm{~m}$ and $12 \mathrm{~m}$. The southern excavation line is adjacent to an existing six storey office building, while the north and east lines are adjacent to the street. The ground model is dominated by tertiary cohesive soils, represented by clays and clays with gypsum interbedding in different state. Locally some sandy silts were investigated. The free swelling index value of clay were $21.0-45.6 \%$ and classified as strongly and very strongly swelling. The pressure of swelling was defined as 100-250 $\mathrm{kPa}$. The first groundwater level developed within the sandy sediments and the second lying deeper within the clay formations developed in sandy silts layers.

Along the existing building a pile wall was designed with CFA $\varnothing 600 \mathrm{~mm}$ piles spaced $650 \mathrm{~mm}$, anchored with strand anchors in two levels. On the remaining part of the trench a berliner wall was assumed with CFA $\varnothing 600 \mathrm{~mm}$ pile columns spaced $2.0 \mathrm{~m}-3.0 \mathrm{~m}$ with timber lagging. In one section it was anchored in one level, while other sections were cantilever. In order to reduce the loading, the area outside the shoring was lowered by slope. 


\subsection{A description of the situation}

Three weeks after start of earthworks, the largest horizontal displacements of the pile wall head reported by 3 measuring points were up to 63 and $127 \mathrm{~mm}$, significantly exceeding the values specified in the casing design. On that day one section of the soldier pile wall was over excavated to the depth $2.5 \mathrm{~m}$ below the anchor level (not installed yet). Once the execution error was detected, the trim was immediately backfilled. In this section the cap beam had not yet been assembled, so the anchors had not been pre-tensioned. The cap beam was assembled two days later. The next day a downpour came and 7 piles tilted or overturned (Fig. 1). The following day, also the shoring with the cantilever soldier pile wall on the other edge of the trench was destroyed over a length of several meters. In this place the earthworks were finished, the lean concrete laid and the installation of the slab reinforcement already started.

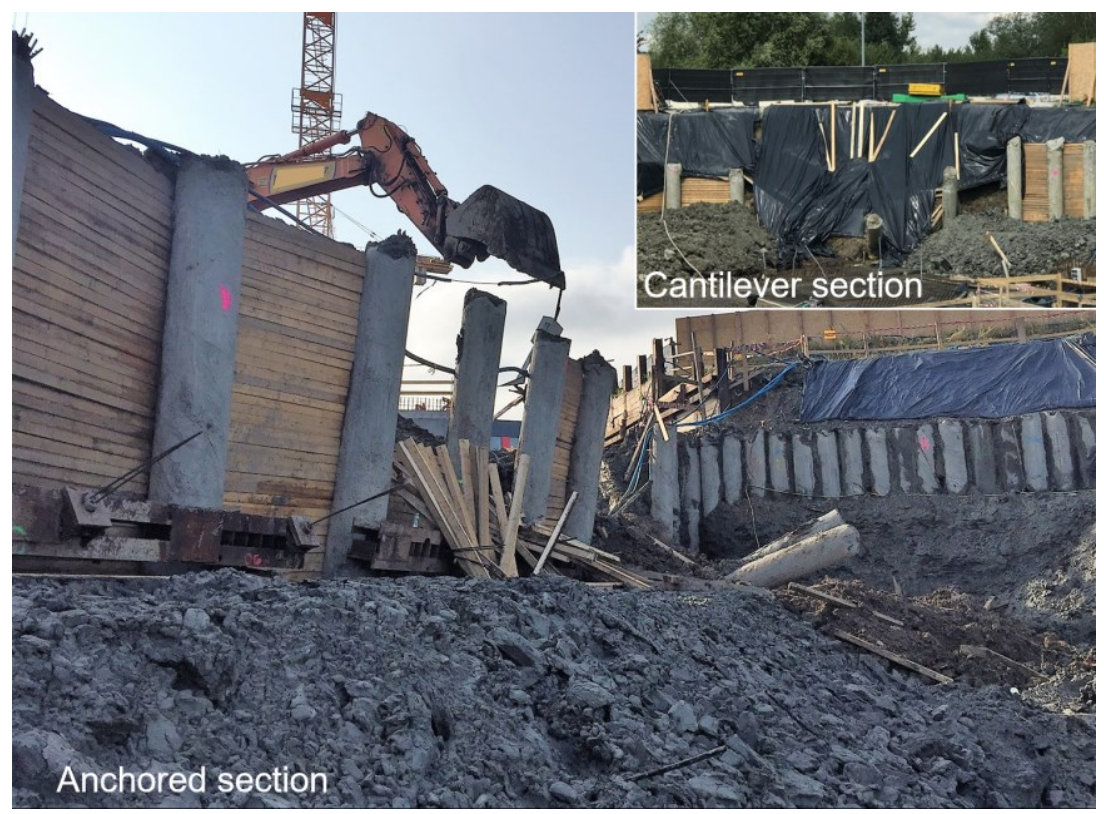

Fig. 1. View of the collapsed sections of soldier pile wall.

\subsection{Analysis of the failure factors}

The analysis of the construction documentation, has shown that damage of the shoring was caused by a combination of several causes, both designing and executive.

The excavation casing has been entirely located in clay described as strongly swelling, thus the designer should have selected sheeting technique preventing access of rainwater and air humidity to such sensitive soils. The soldier pile wall does not meet this requirement, hence swelling clay was exposed to irrigation, as confirmed by the first severe displacement noted during low rainfall and an increase of air humidity. When the rainfall reached $30 \mathrm{~mm}$, the piles were broken. The unfavourable impact of the water was intensified by the slope above the wall, which enabled the flow of rainwater to the backfill space behind the timber infilling. The swelling pressure changed the load pattern adopted in the calculations and significantly increased its value. As a result, displacements quickly exceeded the calculated values. The water moistened also the trench bottom, plastifying clay and reducing the earth resistance. 
Furthermore, in the design, according to the EC-7 [1], the effect of swelling soils has not been included in any way. Considering the very high swelling pressure of clays it could be a critical error. In addition, the relatively high effective cohesion of the soil has been assumed up to $60 \mathrm{kPa}$ (according to the old polish standard PN-B-03020 [2]), which substantially exceeds the in-situ and triaxial test results. This value does not take into account the recognized thin gravel layers exposing the clay for negative impact of water, worsening its parameters. It also means that calculation were carried out on the basis of incompatible normative approaches. On the other hand, the ground investigation report (acc. to EC-7 [3]) has been of a very good quality, so these lacks in the calculation are difficult to explain.

It is also worth noting that the piles in the collapsed soldier pile wall have the largest spacing and the weakest reinforcement. This is due to the assumptions of lowering the top of the piles, however the total height of the excavation remained the same as for other sections. Moreover, the cantilever scheme of the wall is dominant, even if total height is up to $8.0 \mathrm{~m}$ and spacing the biggest. In such structures, the responsibility of a single structural element is very high and the safety margin minimal, increasing the risk of failure, as happened.

One of the critical factors causing the failure was over excavation of the piles by contractor. The water influence could also be minimized if the contractor would have covered the slope with e.g. watertight sheet.

The design and execution of excavation protection did not comply the engineering principles, but also due diligence, resulting from third geotechnical category, how the task was qualified.

\section{Pre-failure state of retaining wall protecting road deep excavation}

\subsection{Design solution and geotechnical conditions}

One of the retaining structures along the new express route, of length nearly $300 \mathrm{~m}$ and the maximum height $30 \mathrm{~m}$ has been designed as a sequence of three parallel anchored pile walls formed (Fig. 2). The pile wall has been made of DFF $\varnothing 40 \mathrm{~cm}$ piles in spacing of $50 \mathrm{~cm}$ with reinforced concrete facing. In the DFF technology a pile is firstly drilled with continuous flight auger, cased. Then, after reaching some harder base, the auger is withdrawn and the remaining length of a pile is drilled with down-the-hole-hammer. The $\mathrm{H}$ beam has been used as a pile reinforcement. The wall has been anchored with tension micropiles of capacity up to $970 \mathrm{kN}$ and length up to $36 \mathrm{~m}$ in several rows, depending on the height. The project also provided drill drains system.

In terms of geotechnical conditions the weathering profile of Carpathian flysch rocks has been presented, mainly shale and sandstone squeaky rock material (with a significant predominance of shale) strongly tectonically deformed, with numerous weaknesses and discontinuity zones. Deeper layers showed clear moisture and shallow underground water levels have been found and local leakage of spring outflows form. The area has been classified as a landslide region. Due to the high unpredictability of ground conditions reported in the indicated area and required reliability of the retaining wall the project was to be executed within the observational method. 


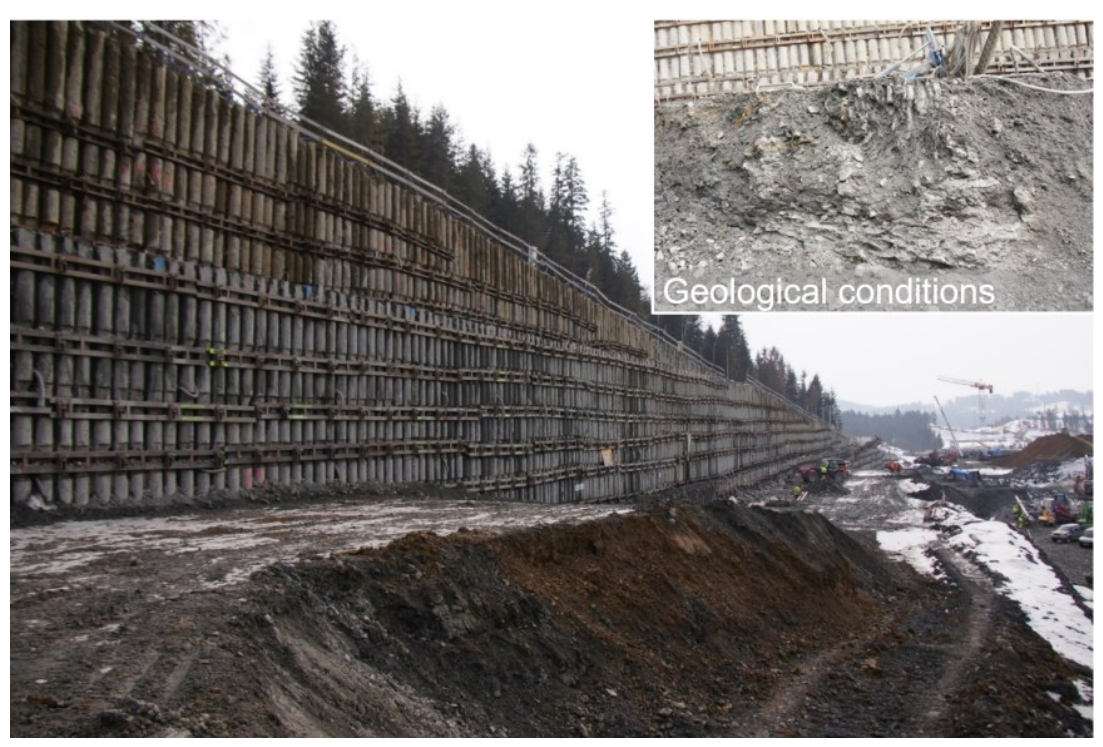

Fig. 2. General view of the retaining wall with ground conditions illustration.

\subsection{A description of the situation}

During works on the site, the designer has been informed about the displacements of the retaining wall of a significant value excessing the limit values for this type of construction, although the contractor has not provided all required monitoring data in due time. The inspection on site revealed in fact some openings of expansion joints in the concrete cap beam above the wall, but as geodetic measurements begun weeks after earthworks had started (at the third and fourth excavation stage), their values were unreliable and difficult to assess.

Also, at the advanced stage of works, the contractor informed the author supervision about significantly worse ground conditions.

Furthermore, after the first incident the designer repeatedly reported negligence and serious deficiencies as well as the means of repair, but the work was still carried out in an improper manner and ever-increasing displacements were shown by the monitoring system.

\subsection{Analysis of the failure factors}

Site visit revealed that project has been executed without the use of observational method, what means without ongoing adaptation of the solution to the actual geological situation assessed continuously and failing to comply the design provisions. The analysis of the situation showed that contractor changed the technology and sequence of operation, what influenced negatively not only the serviceability of the retaining wall, but also gave doubts about it bearing capacity. Some of contractor's arbitrary changes and errors (Fig. 3Fig. 3):

- Switch of the self-drilling technology of the anchorages (micropiles) to the pre-drilling bar anchor without any further modification required by the tender documentation and standard [4], such as: drilling with the casing on the whole length, injection and reinjection from the bottom, bigger diameter of the drill bit etc. In this case, the final bearing capacity comparable to the self-drilling technology (as primarily designed) could not be achieved, not mentioning the diameter and strength of the grout body (because of the lack of stability of the hole), as well as corrosion protection, especially that the bars were installed without any spacers. 
- Use of the connectors without internal stoppers to control the screw-in depth of the joint reinforcement so as to guarantee its continuity and load capacity during operation.

- The work should have been carried out in stages, evenly removing soil layers with thickness of one anchor level (ca. $1.5 \mathrm{~m}$ ), then installing anchors, cap beam and anchor micropile head (so the anchorage could start working) and after 7 days next stage of earthworks could be performed. On site, the earthworks step was up to 2-3 anchor levels, so the wall was excavated up to $6 \mathrm{~m}$ without anchoring, what changed dramatically the static scheme.

- Deviations higher than permitted resulting in change of load scheme on anchors (shear) and increasing the displacement (because of big clearance under the anchor head).

- Lack of quick drainage of water from the area of works resulting in changes in its consistency, which leads to reduction of soil resistance and change of static scheme of retaining wall.

Moreover, the monitoring system was completely chaotic and unreliable: the targets were localized on thin bars what made it vulnerable, the measurements started too late, load indicators were installed at the anchors two stages after they started working (therefore the anchors were firstly relieved and the indicator measured an undefined increase in the load).

These actions have made it impossible to assess the safety level and define the cause of displacement limits exceedance. Meanwhile, it is certain that further execution of the works in a manner inconsistent with the design and state of the art may lead to structural failure.



Fig. 3. View of the retaining wall with presentations of some of the execution errors. 


\section{Failure condition of road slope cut protected by soil nailing}

\subsection{Design solution and geotechnical conditions}

The express route in the section concerned has been routed in excavations with a depth up to $12 \mathrm{~m}$. As an element strengthening and ensuring the overall stability of the cut slopes, in-depth ground reinforcement with soil nails long up to $12 \mathrm{~m}$ in space $1.5 \times 2.0 \mathrm{~m}$ and high-strength steel mesh with a system ensuring fast and permanent greening of slopes has been designed. The drilled drains system was also the part of the structure. The clayey silt with rock fragments (mainly shale and locally shale with sandstone) was expected in the ground. In the area of the indicated slope no continuous water level was found, but leakages were reported. Due to the previous designer's experience from projects carried out nearby, as the ground condition was expected to be similarly difficult, the cutting was also to be executed within the observational method.

\subsection{A description of the situation}

During the field inspection it was found that numerous landslides of different area and depth were formed (Fig. 4), some of the shallow slide character, some deep-seated. There were also many tension cracks above the slope visible, which testify to the progressing of geodynamic process. Significant number of groundwater outflows were also observed, liquifying the soil around and forming local slides.

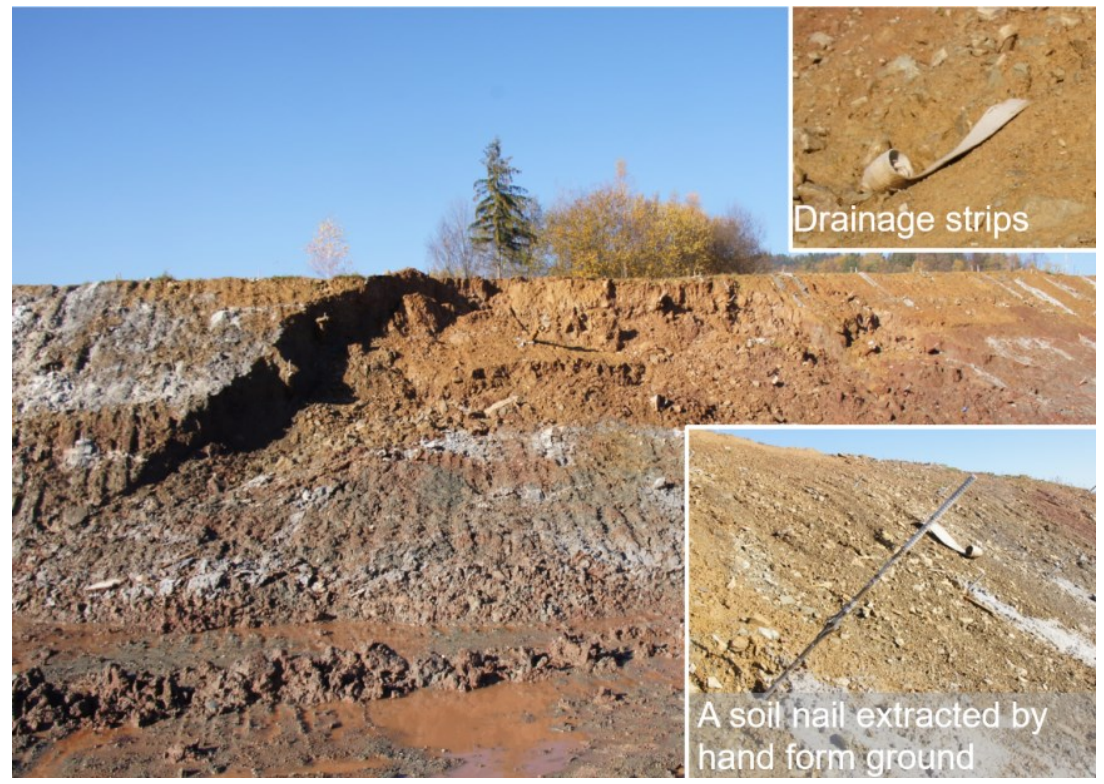

Fig. 4. Landslide on the slope and detail of badly installed soil nails and improper drain technology.

\subsection{Analysis of the failure factors}

After distressing phenomena were reported, the designer revealed that works were carried out with number of the deviation from the technology and sequence described in the project.

Firstly, the soil nails were installed using the pre-drilling method instead of self-drilling as designed without proper modifications. Although both methods are acceptable, to be 
regarded as equivalent special actions must be taken to obtain the same load bearing capacity despite lower skin friction [5] (cf. 0). Also, serious installation errors were revealed, resulted in no grout body formed, so the soil nails had almost no capacity (in the Fig. 4. Landslide on the slope and detail of badly installed soil nails and improper drain technology $6 \mathrm{~m}$ long soil nail extracted from the ground by bare hand (!) is shown). Furthermore, the soil nails chosen by the contractor had smaller load capacity and flexural stiffness than specified in the project.

The drains were described in the tender as a perforated drainage pipe placed in the borehole, protected with geotextiles, while the contractor used drainage strips introduces directly into the ground without the pipe, which shows incomparably worse draining effect of the rock mass, significantly worsening geotechnical conditions. This fact is exceptionally meaningful, as the regulation of water relations has a critical impact on slope stability, as well as maintenance costs and aesthetics.

According to the design and appropriate standard [5], the slope was to be formed with a top-down system in stages: excavation to the depth of the working level (soil nail row), soil nail installation (and drainage if applicable), fixing the facing. Actually, this sequence was disturbed, as the contractor carried out earthworks to the depth of as many as five working levels, and only then installed soil nails on (as evidenced by the very uniform traces of an excavator bucket visible in the photograph, cut through with later installed soil nails). In addition, the contractor did not install the facing system, which is critical for the cooperation of the nails and the surface stability. Undoubtedly, this procedure contributed to degradation of the stability conditions.

Additionally, as there were no surveying or geotechnical monitoring reports and no target were noted on site, it means none monitoring programme was conducted by the contractor. Also the contractor had not reported that ground conditions were significantly different than assumed in the design. The dominant layer was highly weathered shales, extremely worsening the shear resistance in contact with water, what in the situation of lack of the properly working drainage system caused serious change of the assumptions of static and stability calculations.

Thus, not only the requirement of observational method (as stated in the design documentation) was not fulfil, but early recognition of mass movements and appropriate intervention was prevented.

In summary, the works has been executed with massive number of unauthorised changes, incompatible with documentation, reducing the effectiveness of stabilization structure and worsening its stability. It is also worth mention, no remedial actions have been taken by the contractor, therefore landslide could proceed, endangering the safety of employees, increasing costs and prolonging work.

\section{Failure of soil nail structure within road slope cut protection}

\subsection{Design solution and geotechnical conditions}

While constructing the new city bypass, several deep cuts had to be done. The height of the slopes cut was up to $15 \mathrm{~m}$. Slope within deep cuts were designed as soil nailed structures with flexible facing. Ground conditions were expected to be quite good - subsoil has been documented as quaternary sands, silts and silty sands with no uniform aquifer. Although the risk of local seepages has been expected. In such conditions the slopes protection has been designed as soil nail structure, self-drilling hollow bar soil nails type 30/11 has been installed, in lengths from 6 to $15 \mathrm{~m}$ and the raster set to $1.5 \times 1.5 \mathrm{~m}$. The high strength steel mesh has been chosen as a facing, as slopes were to be 'green finished' with grass. 
Dewatering system consisted of drilled drains with basic layout of two levels with cc spacing $3 \mathrm{~m}$. Besides, additional drains were foreseen to be installed in areas of seepages to control the flow of ground water. The main idea was to take out the water as soon as possible, as silty soil is vulnerable to increased humidity. The decision where to install additional drains has been prescribed as surveyor responsibility. As seepage areas was was possible to determine at the excavation phase of works only, it the contractor's works manager was responsible for reporting to the surveyor all areas found with excessive humidity. That is quite often used design approach, known as active design, when engineers are allowed to engineers modify the design if the revealed ground conditions are not as assumed in the design.

\subsection{A description of situation}

The geotechnical designer has been informed about the difficulties at the site when first soil nails started to break. The inspection onsite revealed severe problem with overall stability at one section of deep cut of a length of app. $60 \mathrm{~m}$. The excessive displacements of the slope were clearly visible. Within this section, all elements of structure were obviously overloaded - the nail heads had been sunk (sucked) into the ground, app. 40-50 cm below slope face (Fig. 5). In several points the hollow bars were broken, as well as single eyes of the steel mesh.

Despite significant displacement (the slope base line intruded far beyond the road perimeter) and single element failures, the construction still has been resisting, holding up the ground masses. In general, the construction behaved as monolithic retaining structure, that moves as a one block. Luckily, the concept of nailed structures as inner reinforcement of ground mass, proved its correctness. The structure has been deformed but still able to hold up itself without inner failure and hold up all infrastructure above deep cut: houses and road, intact. Further inspection revealed that soil conditions were significantly worse than described in geological report and encountered at other sections of deep cut. The areas of increased moisture were easily observed at the slope face. The soil itself, coming out of breached facing, was almost liquified. Further, no drains were installed within the slope, except the ones of basic layout.



Fig. 5. General view of the deformed slope with detail of the overtensioned soil nail and steel mesh. 


\subsection{Analysis of failure factors}

Although the reasons of failure have seemed to be obvious, the material tests were commenced. The samples of hollow bars and steel mesh were taken to prove declared values of tensile strength. All tests were positive. Rejecting the influence of any deficiency of reinforcement (nails and mesh), the reason of failure was clear - soil conditions far below the ones, that have been taken into stability calculations. As in terms of lithology the soil has not differed from expected, the excessive moisture has been pointed as a source of the problem. This was due to lack of additional drains, that could have taken increased inflow of ground water to this section of deep cut.

The technical reasons of failure stage were quite easy to point out. The same cannot be said about formal reasons. Definitely the active design didn't work this time. Following the jobsite documentation and interviews with involved people it turned out, that there was a lack of information flow between contractor's responsible person and surveyor. The first one hasn't been reporting the need for additional drains in fear of being accused for unnecessary increase of the costs. The surveyor in turn, hasn't been a professional within geotechnics and laid his trust into the contractor's manager as most experienced in this field. The reason why the geotechnical designer has been notified earlier, or even on regular basis (as it was prescribed in technical specification) remains unknown.

\section{Anchored pile wall for express route deep cut}

\subsection{Design solution and geotechnical conditions}

The trace of the new express route section has passed through several hills and mountain sides. Therefore, various different retaining constructions had been designed. The described case refers to the tie-backed pile wall, that has been used to secure one of the cuts. The geotechnical conditions were complex, as the route is located within Carpathian flysch. In terms of geology, the mixture of mudstones slates and weathered sandstone interbeddings were found within the excavation. The slates and schists were poor quality, thin-layered, easily intended and crumbled under finger pressure. The sandstones were moderate to highly weathered, UCS app. 2-10 MPa, developed as 10-30 cm thick layers. In general, the rockmass was a mudstone type with app. $20-30 \%$ share of sandstones.

In terms of technical solution, the pile wall has been chosen as a retaining structure. The tension micropiles have been chosen as a tie-backs, to provide required stability. The maximum height of the retaining structure has been set to $7 \mathrm{~m}$. Calculated pile length varied from 4,8 up to $13 \mathrm{~m}$, as the wall declined to the both sides to the height of app. $4 \mathrm{~m}$ at the both ends. The piles were DFF type and the $\mathrm{H}$ beam was used as a pile reinforcement. The piles were $40 \mathrm{~cm}$ diameter and cc spacing of $50 \mathrm{~cm}$. Considering overall conditions, hollow bar tension micropiles have been designed as tie-backs. The aim was to improve the rockmass by this mean (to petrify fissured rockmas with cement grout) and ease $\&$ speed of installation was a surplus. The tension micropiles were deployed in three levels, in spacing $2.0 \mathrm{~m}$ or $1.5 \mathrm{~m}$ depending on wall section height. Hollow bars type 40/20 and 40/16 in lengths varying from 12 to $18 \mathrm{~m}$ have come out of static calculations.

\subsection{A description of situation}

First difficulties occurred at a stage of pile installation. The subcontractor's equipment turned out to be inappropriate to such ground conditions. The main issues were the stability of the borehole and possibility to reach designed length. Despite those adversities the subcontractor 
has finished his job. Within the next stage, another subcontractor commenced hollow bar micropiles installation. Tension micropiles were installed successively with excavation. However, the installed tension micropiles were different type of those prescribed in technical specification, as contractor has changed the supplier in search for savings. The subcontractor responsible for micropiles installation hasn't been able to finish his job.

Shortly after excavation below second level of tie-backs, the tension micropiles within second level started to break (Fig. 6). The subcontractor replaced broken micropiles with new ones, which is some cases also failed. The wall started to lean towards the excavation. Reaching the level of layer three (the last one) of tie-back turned out to be impossible. The crown displacements od the wall were increasing rapidly, reaching $87 \mathrm{~cm}(!)$ at the worst phase. This failure caused increased load onto micropiles and construction within the first level. In such conditions, the surveyor together with the designer decided to halt all further works and support the structure with emergency ground abutment. The excavation has been filled back to the $1 / 3$ of its current height, which is up to the first level of tie-backs $(2 / 3$ of the excavation depth was filled back again). After thorough research on failure reasons, the repair design has been implemented with replacement construction. There was no possibility to save and use the former one, or even its single elements.

\subsection{Analysis of failure factors}

The investigation for failure reasons started directly after the emergency abutment has been created. Simultaneously to the technical inspection, double check of static calculations has been ordered. The investigation covered the inspection of executed works and laboratory tests of the materials used. It revealed some interesting points.

The tensile test results (trial loads) of micropiles have shown, that several tension micropiles have reached only $20 \%$ of their design load. Next, the independent laboratory tests have shown, that hollow bars used do not reach their declared values of safe working load. Finally, the piles that were laid open after the repair construction has been done, revealed several imperfections - some of the piles were shorter than designed, some of them didn't have continuous concrete body and some had totally exposed reinforcement at lower section, completely without any concrete. This mixture of poor quality of works and materials used have created a huge lack of required strength, as well as strictly chaotic distribution of loads within entire construction.

This case shows clearly the importance of quality of the works as well as the influence of reliability of materials that are used for construction purposes. 


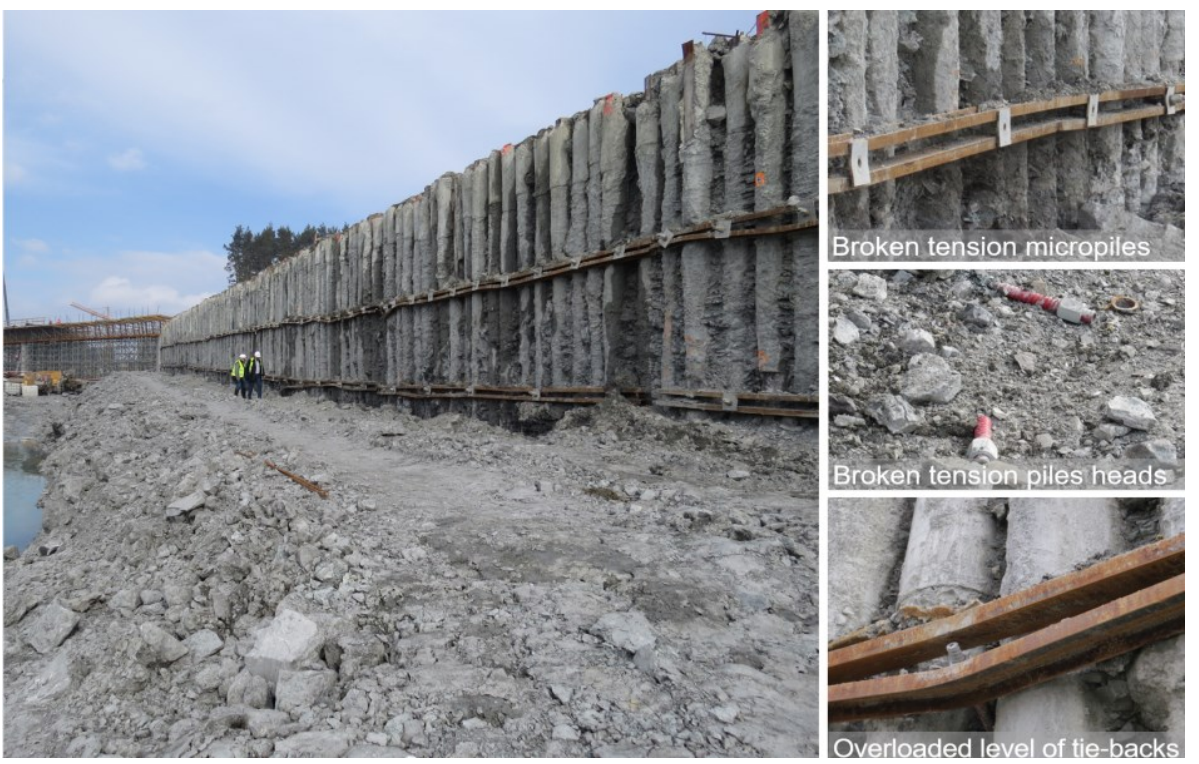

Fig. 6. General view of the construction with emergency abutment and details of damaged elements.

\section{Summary}

With this paper, the authors want to recap some observations and experiences gained during their professional activities. It is thought-provoking, how many failures come out within geotechnical works. Especially compared to other branches of construction industry. Of course it somehow related to specific conditions of geotechnics, where construction meets pure, living nature which is sometimes hard to describe with parameters and fit into numbers. But on the other hand - soil investigation tools and procedures are highly accurate and designing/modelling tools very sophisticated and precise. One investigates ground conditions more carefully and designs more carefully with help of different codes. Yet, the failure ratio is puzzling high.

This paper discloses the types of risk to be handled by geotechnical works and reveals some sources of those risks. Analysed cases lead to a conclusion, that main risks can be assembled and pointed:

- Design errors,

- Poor execution of the works, flagrant executional errors,

- Ignorance of design and technical specification statements,

- Reckless changes of the prescribed technology and/or materials,

- Lack of adequate supervision, quality control and monitoring on site,

- Lack/disturbance of information flow between parties involved in construction process.

The authors experience shows, that design errors occur rather occasionally. And even the longest list of safety factors isn't enough to cover other risks. The authors have looked through the nature of above listed risks and history of many contracts from different sides: as involved party or just observer. The conclusion is, that the source of the problems very often comes out of formal and economic conditions. There are several week points within formal regulations that makes all projects so vulnerable to lack/disturbance of information flow, which seems to be one of the most often met source of trouble. In this term, one can find a formal gap: 
- In the regulations and provisions of contracts, there is no strict 'map of responsibility' between involved parties, which leads to passive behaviour of surveyor's or contractor's service and lack of continuity between the design and construction process or even disregard for the designer's participation in the decision-making path.

- There is no strict and clear list of competence and experience to provide appropriate supervision service (to a lesser extent this applies to design and contractor personnel), both in the public regulations and European standards. Quite often one can meet site inspector which is brilliantly experienced within e.g. bridge construction, but barely aware of all geotechnical issues. This leads to passive behaviour as well, 'better not to lean out' attitude.

Having those issues not solved out by any formal regulations will maintain current status quo and contribute to further failures.

In terms of economic conditions - these seem to be related tightly again with formal ones. It is visible in procedures and nature of state public tenders, which prefer instant economic result, commonly known as 'saving' rather, than well balanced: price and serviceability of final product (construction). The continuous price pressure applied to the contractors forced them to seek fake savings - this results in poor quality of works and materials. It is somehow ironic, that such attitude is accepted by investor's representatives who has no formal basis (because of the type of public tender conditions) to enforce proper technical correctness.

Hopefully, this paper with clear examples of most often encountered failures combined with highlighted risks and sources of problems can initiate the change. The change for better, more transparent and fair geotechnics.

According to the authors' intention, the specific investments described in this paper are to serve only as example for problem analysis, for this reason any information that can be used to the precise identification of the participants in these investment processes have been removed.

\section{References}

1. PN-EN 1997-1:2008: Eurocode 7: Geotechnical design - Part 1: General rules

2. PN-B-03020:1981: Posadowienie bezpośrednie budowli. Obliczenia statyczne i projektowanie [in Polish]

3. PN-EN 1997-2:2009: Eurocode 7 - Geotechnical design - Part 2: Ground investigation

4. PN-EN 14199:2015-07: Execution of special geotechnical works - Micropiles

5. PN-EN 14490:2010: Execution of special geotechnical works - Soil nailing

6. Archival materials (geological, hydrogeological, geotechnical, design documentation, records of construction logs, results of measurements and observations, expert opinions) [in Polish] 